Article

\title{
Development of a Novel Friction Model for Machining Simulations in Unidirectional Composite Materials
}

\author{
Oscar Seward $^{1,2, *}$, Fernando Cepero-Mejías ${ }^{1,2} \mathbb{D}$, J. Patrick A. Fairclough ${ }^{3} \mathbb{D}$ and Kevin Kerrigan ${ }^{1}$ \\ 1 AMRC with Boeing, Advanced Manufacturing Park, Wallis Way, Catcliff, Rotherham S60 5TZ, UK; \\ f.cepero@sheffield.ac.uk (F.C.-M.); k.kerrigan@sheffield.ac.uk (K.K.) \\ 2 Industrial Doctorate Centre in Machining Science, The University of Sheffield, Sir Frederick Mappin Building, \\ Mappin Street, Sheffield S1 3JD, UK \\ 3 Department of Mechanical Engineering, The University of Sheffield, Sir Frederick Mappin Building, \\ Mappin Street, Sheffield S1 3JD, UK; p.fairclough@sheffield.ac.uk \\ * Correspondence: o.seward@amrc.co.uk
}

Citation: Seward, O.; Cepero-Mejías, F.; Fairclough, J.P.A.; Kerrigan, K. Development of a Novel Friction Model for Machining Simulations in Unidirectional Composite Materials. Polymers 2022, 14, 847. https:// doi.org/10.3390/polym14050847

Received: 4 January 2022

Accepted: 8 February 2022

Published: 22 February 2022

Publisher's Note: MDPI stays neutral with regard to jurisdictional claims in published maps and institutional affiliations.

Copyright: (C) 2022 by the authors. Licensee MDPI, Basel, Switzerland. This article is an open access article distributed under the terms and conditions of the Creative Commons Attribution (CC BY) license (https:// creativecommons.org/licenses/by/ $4.0 /)$.

\begin{abstract}
Constant coefficients of friction (COFs) are currently used in the literature to describe the contact mechanics between tool and workpiece for finite element (FE) machining simulation of carbon fibre-reinforced polymers (CFRPs). However, these are solely based on closed-loop tribology experimentation, which insufficiently represent machining conditions. To overcome this gap in the knowledge, this work proposes a novel experimental open-loop tribological testing method to produce a dynamic FE friction model for CFRP machining simulations. The newly proposed dynamic friction model is based on a function of fibre angle, contact pressure and slip rate, and it has been validated to both experimental results and constant COF FE simulations. The main aim of this article is to create a link between machining, tribology and FE simulation, by implementing cutting-edge tribological testing that results in highly accurate FE simulations. This dynamic model has been shown to improve the accuracy of open-loop tribological simulations, giving confidence in future implantation in CFRP machining simulations.
\end{abstract}

Keywords: carbon fibre; machining; fiction; tribology; computational modelling

\section{Introduction}

Carbon fibre-reinforced polymers (CFRPs) are being increasingly adopted in many engineering applications. CFRPs' unique ability to be manufactured to near net shape, vast weight savings, increased strength and resistance to fatigue and corrosion make them the obvious choice for aerospace, automotive and renewables. However, the fundamental contact mechanics that occurs in machining is still relatively undefined. These tool-workpiece interactions give rise to extremely high pressures, temperatures and slip rates, thus affecting the machined surface and further affecting the contact between tool and surface. Measurement and quantification of these machining variables are extremely difficult to do experimentally, due to the inaccessibility of the contact region. FE simulations have the capacity to determine these otherwise unknown variables and graphically represent the entire contact interface. Cutting and thrust force predictions are used to quantify a simulation's accuracy and validity (Figure 1). Well-validated machining simulations can then be used to justify tool design parameters, cutting geometry (rake/relief angles) [1], coatings, coolant and machining strategies [2]. The predictive capability of a given FE simulation can therefore provide a significant benefit, both in enabling the development of advanced cutting tools and cost savings over experimental testing [3]. Orthogonal cutting simulations are where most researchers have concentrated their efforts Table 1. 


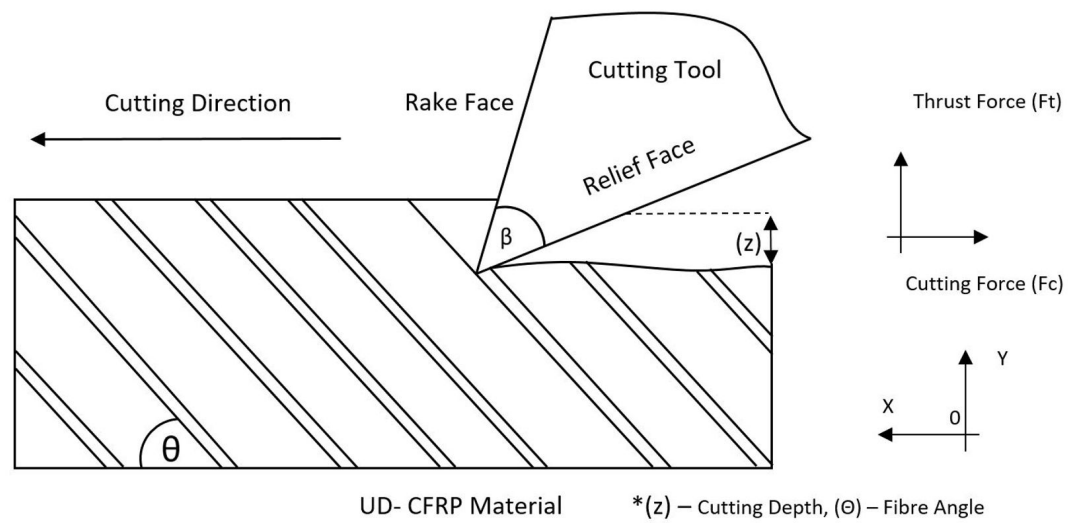

Figure 1. CFRP orthogonal cutting diagram with forces.

Material models are extensively researched aspects of machining simulations, with developments constantly improving validation quality. These mathematical representations of a material in the numerical domain describe how the material behaves under a given force, through elastic response, damaged initiation, plastic deformation and full damage. The most renowned models for prediction of fibre and matrix response within unidirectional composite materials are the Hashin [4] and Puck [5] models. These models are material dependent and many properties have to be tested experimentally to increase simulation validity. Recent developments in material modelling for CFRPs include linear damage propagation, calculated using the material's fracture energy [1]. This is much more representative than purely damage initiation and element deletion methods previously proposed [6]. Similarly, friction models and COF values have been shown to greatly affect the accuracy of cutting force measurements of machining simulations [7,8]. Apparent COF (ACOF) values and material-linked friction models in metal cutting simulations have been studied more extensively than CFRP materials [9]. Due to the lack of stick-slip contact mechanism in CFRP machining, chip formation characteristics and the complex anisotropic material structure of CFRPs, no comparisons can be made between metallic and composite machining approaches or simulation strategies [10]. Frictional effects on secondary valuation criteria, such as temperature and frictional energy in CFRPs, have been known to be an area of concern for many years [11]. The simplest description for a mathematical model of the frictional forces on a macroscopic scale is the Coulomb law, which states the ratio of tangential force $F_{t}$ and normal forces $F_{n}$ [12]. This relationship gives the proportionality between the forces and the friction coefficient.

$$
\mu_{\text {app }}=\frac{F_{t}}{F_{n}}
$$

Frictional effects can be separated into two constitute parts, an adhesive term and a deformative term [12]. When using frictional data with finite element (FE) simulation, the adhesive friction coefficient (ADCOF) should be used, as the FE solver computes the contact's deformative friction coefficient (DCOF) from the deformation of the domain's elements. This is an aspect that has been overlooked by a number of researchers in previous studies, as shown in Figure 1.

$$
\mu_{A C O F}=\frac{F_{t}}{F_{n}}=\mu_{A D C O F}+\mu_{D C O F}
$$

The most common method of implementing frictional data is achieved by applying a constant Coulomb fiction coefficient value. When doing this, the user restricts the model's ability to capture interdependencies, which are known to affect machining forces such as fibre angle $(\theta)$, pressure $(p)$, slip rate $(V)$, temperature $(T)$ and tool edge radius $(r)$. Therefore, the ACOF should be represented as a function of these variables. 


$$
\mu_{\text {app }}(A C O F)=f(\theta, p, V, T, r)
$$

In order to account for these factors, their effects have to be isolated and quantified. Friction coefficient identification and testing have been a keen area of research, with many testing methods developed. Traditionally, to assess a pair of materials' ACOF, a closed-loop tribometer would be used, such as a pin on disk. This apparatus involves a rotation disk of one material and a pin on a predetermined size of another material. The pin is then pressed into the disk with a given force determined by a load cell, and with a ratio of forces, the ACOF is then calculated.

There are many disadvantages to this approach when using the calculated ACOF for a machining simulation. The maximum capable contact force and slip rate are far lower than those present in an industrial machining operation. Another factor which is not representative of machining is the wear track, as the pin drags over the same wear track throughout the trial. Inherently, machining is a material removal process, which means that fresh material comes into contract with the cutting tool at all times. Sung et al. and Nayak et al. are the only notable closed-loop tribological studies of CFRPs, showing the effects of $\mathrm{COF}$ and fibre angle $[13,14]$. Although these studies were investigating the effects of glass fibre-reinforced polymers (GFRPs) and high-speed steel (HSS) on ACO,F it can be seen from Figure 2 that ACOF is clearly affected by fibre angle.

(A)

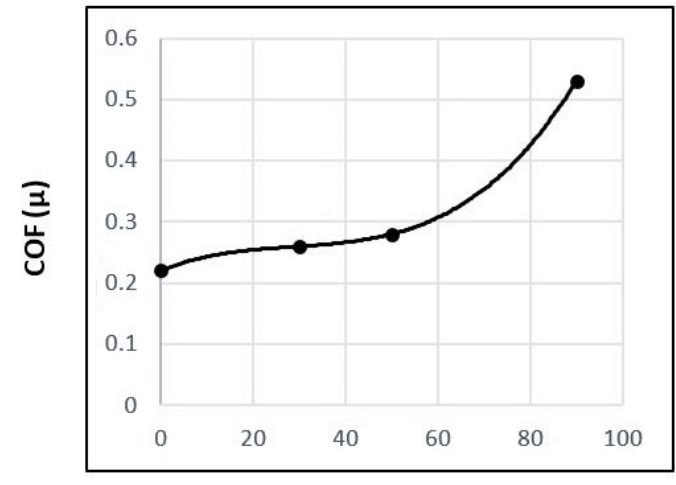

Fibre Orientation Angle ( $\theta)$

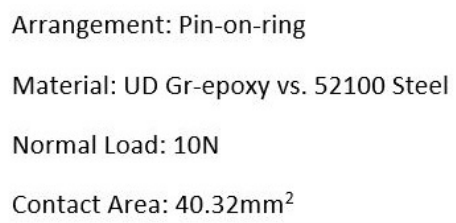

Figure 2. ACOF as a function of fibre angle [13,14].

Table 1 highlights the difference in (CFRP/WC) ACOF values used throughout FE orthogonal cutting simulations carried out in previous studies. The mentioned authors have referenced the pin and disk studies previously discussed as their source for ACOF values. Others have chosen to take an average of previous cited ACOF values [15]. Some have even discussed using various $\mathrm{ACOF}$ values to match force responses with experimental data $[11,16]$. 
Table 1. Orthogonal cutting COF comparison table for previous simulations.

\begin{tabular}{ccc}
\hline Authors & Publication Date & ACOF Used \\
\hline Ramulu et al. [17] & 1997 & 0.4 \\
\hline Arola et al. [18] & 2002 & 0.4 \\
\hline Bhatnagar et al. [16] & 2014 & N/A \\
\hline Mkaddem et al. [15] & 2008 & 0.3 \\
\hline Lasri et al. [19] & 2009 & 0.5 \\
\hline Santiuste et al. [11] & 2010 & 0.5 \\
\hline Santiuste et al. [20] & 2011 & 0.5 \\
\hline Zenia et al. [21] & 2015 & 0.4 \\
\hline Benhassine et al. [22] & 2018 & 0.3 \\
\hline Cepero et al. [1] & 2019 & 0.2 \\
\hline
\end{tabular}

Friction separation methods have been overlooked by all the studies motioned above, with the apparent $\mathrm{COF}$ (ACOF) as the value used in simulations instead of ADCOF values. One analytical method of achieving friction separation was developed by Challen et al. and more recently was implemented by Mondelin et al. for machining of CFRPs [23,24]. This ploughing model showed promising results for metal ploughing; however, this utilises a method developed by Johnson and Rowe [23] for standing wave theory. A few assumptions are needed for this elastic recovery model to be valid; one notable assumption is that no material spring back is considered.

This assumption was justified by Mondelin et al. due to the fact that CFRPs have a low Young's Modulus and the effects of normal force and therefore the contact pressure on results, so neglecting spring back effects was thought to be adequate. However, it has been shown by preliminary cutting trails that for orthogonal cutting, the spring-back for a $200 \mu \mathrm{m}$ depth of cut can be in the region of $75 \mu \mathrm{m}$ [25]. Another analytical model proposed by Lafaye et al. is considered to be more appropriate as it is designed for a spherical tipped pin on a material with elastic recovery. This model was used to good effect by Klinkova et al. to develop a velocity-dependent coefficient of friction for machining CFRPs [26]. Although a good improvement upon the purely plastic model used by Mondelin et al., analytical models are known to have high sources of error for this reason, and therefore a novel method has been proposed, using a numerical simulation to inversely separate the frictional COFs.

A number of more recent studies have tried to close the gap between the use of these outdated pin of disk trials and shine a light on the misuse of ACOF values in FE machining simulations. Open-loop tribometers are thought to be the cutting edge of tribological study for machining applications - these systems take advantage of highly accurate machining centres equipped with a pin of predetermined geometry and piezoelectric dynamometer to collect forces. This allows the user to design a tribological test that best represents the machining situation that is being investigated, with much higher forces, speeds and presentation of fresh material to the workpeice-a vast improvement upon the closedloop systems. Figure 3 demonstrates how the forces from the dynamometer are used to calculate the material pair's ACOF. Comparing this diagram to the one of orthogonal cutting (Figure 1), major similarities can be drawn. By replacing the cutting tool for a pin, the cutting forces are isolated from the contact, leaving only the ploughing effect-vastly decreasing the complexity of the system, thus allowing for the frictional forces to separated from the cutting forces as best as possible. 


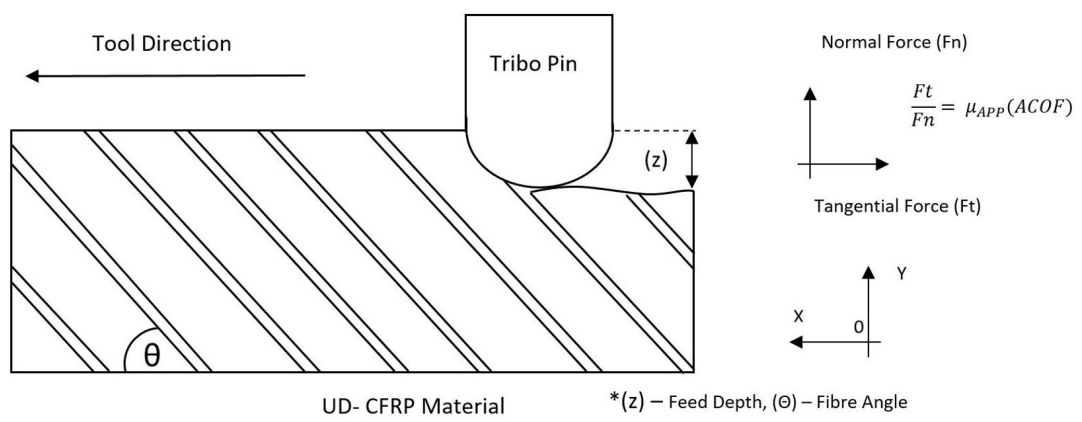

Figure 3. CFRP open-loop tribometer diagram with forces.

Constant sampling of these forces allows for dynamic friction models to be developed, in which friction is not a contact value but a function of a number of other variables (Equation (3)). Mondelin et al.'s novel approach using an open-loop tribometer with CFRPs highlighted that apparent COF can be sliding velocity dependent, and was a first of its kind [24]. Pressure was not seen to influence apparent COF response, although this is thought to be due to the use of the Zemzemi approximation (Figure 4) with composite materials. Due to the high levels of material spring-back in CFRPs, measuring the wear scar after the contact has occurred to calculate contact pressure is thought to be full of error and uncertainty. Klinkova et al. and Chardon et al. showed that apparent COF can be affected by sliding velocity in short fibre composite materials [26,27]. Voss et al. indicated that roughness and fibre angle also affect ACOF. All findings are intuitive and realistic, further displaying the oversimplification of the use of a constant COF in any FE cutting simulation. $\mathrm{Xu}$ et al. carried out both an experimental and a numerical study into the apparent COF effects for CFRPs. Normal force was shown to affect the apparent COF with an exponential decay and a steady-state region after $100 \mathrm{~N}$ and up to $250 \mathrm{~N}$. However, using normal force to derive a dynamic ACOF is case specific. Depending on the pin size used, the force response will be different, with the only method to overcome this being using pressure to normalise the results. The material model used in this study is the maximum stress model with no damage propagation, which is a relatively basic approximation of the material response. Given the previous work in the field, the main aims for this study are to successfully develop an open-loop tribometer, in order to develop a dynamic friction model for CFRPs that is a function of slip rate, fibre angle and pressure.

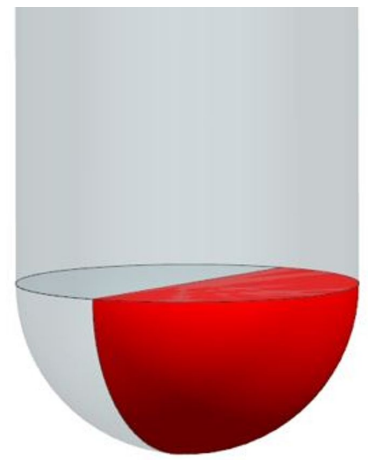

Estimated Contact Pressure:

$$
\begin{gathered}
P \approx \frac{F_{n} 8}{\pi W^{2}} \\
W=\text { Wear Track } \approx \frac{\pi w^{2}}{8}
\end{gathered}
$$

Figure 4. Geometric approximation for pressure proposed by Zemzemi [28] and implemented by Mondlein [24].

\section{Experimental Work}

\subsection{Setup and Procedure}

A DMG Evo 40 linear 5-axis machine and A Kistler (9139AA) compact multi-component dynamometer were used along with a Kistler charge amplifier, which is capable of reading forces up to $30 \mathrm{kN}$ and a sampling rate of $1 \mathrm{MHz}$. Samples of UD-CFRP with Toray T700SC fibres and a XPREG XC130 resin system were manufactured to $150 \times 50 \times 6 \mathrm{~mm}$ with fibre 
angles of $22.5^{\circ}$ to $157.5^{\circ}$ in increments of $22.5^{\circ}$. These were aligned though the $\mathrm{x}, \mathrm{z}$ plane with $0^{\circ}$ were placed on the $\mathrm{x}:(1,0)$ a tool moving from $\mathrm{x}:(-1)$ to $\mathrm{x}$ : (1) Figure 5.

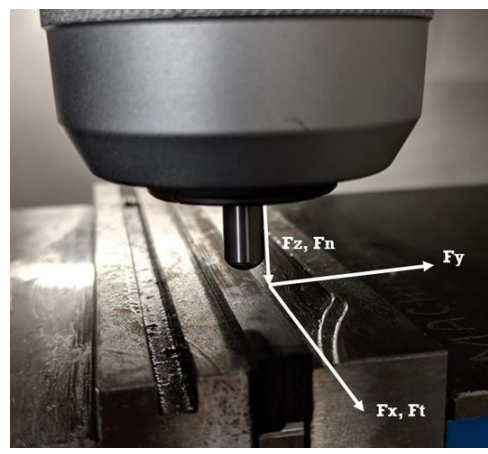

Figure 5. Axis of force direction.

A WC uncoated pin with a radius of $3.25 \mathrm{~mm}$ was used to contact with the CFRP surface. Indent depths were at $100 \mu \mathrm{m}$ and $250 \mu \mathrm{m}$, and used along with slip rates of 1 to $15 \mathrm{~m} / \mathrm{min}$, increasing in $5 \mathrm{~m} / \mathrm{min}$ increments.

Pressure measurements were post processed by assuming the machine tool was perfectly accurate and stiff, which was possible because the in feed $(Z)$ was controlled throughout the trial. This then allowed the use of a geometric relationship of a sphere, with (z) as the feed depth and (r) as the pin radius in Equation (18).

$$
\begin{aligned}
& A=2 \pi r z \\
& P=f_{n} / A
\end{aligned}
$$

\subsection{Experimental Results}

Fibre angle, contact pressure and slip rate-dependent ACOF data are displayed in Figure 6. The effects of each variable are difficult to quantify in $(x, y)$ plots, because of the interdependence between the variables. For this reason, multi-linear regression (MLR) has been carried out to develop an empirical approximation of the factors. However, in more qualitative terms, a definite change of ACOF as an effect on fibre angle can be seen, with $90 \theta$ resulting in the highest $\mathrm{ACOF}$ value, which agrees with both closed-loop studies previously discussed $[13,14]$. Effects of feed and therefore pressure are also apparent-higher feeds yield higher ACOF values, which was expected.

The effects of sliding speed are more difficult to see, showing a minimal effect on ACOFthis is most likely due to a limitation of the maximum available sliding speed $15 \mathrm{~m} / \mathrm{min}$. Higher speeds of $50 \mathrm{~m} / \mathrm{min}$ were achievable with the current setup, although at a cost to the machine's accuracy in both feed and speed. Further work is needed in this area with the possible inclusion of a CNC Lathe instead of a 5 axis machining centre to achieve accurate speeds of $500 \mathrm{~m} / \mathrm{min}$.

A multi-linear regression (MLR) algorithm was used to empirically fit the experimental ACOF data. The MLR was carried out using MATLAB's 'regress' function-this allowed for a dynamic APP COF to be created with respect to a given fibre angle $\left(F_{i}\right)$, pressure $\left(P_{i}\right)$ and cutting speed $\left(V_{i}\right)$. Table 2 gives insight into the dominance of each factor, with pressure and fibre angle being by far the most dominant factors, which agrees with the graphs above. The quality of fit in general was acceptable, with an R2 of 0.789 . Velocity has been shown to have minimal effects on ACOF within the 1 to $15 \mathrm{~m} / \mathrm{min}$ range; however, this does not represent the effects at much higher speeds.

$$
\mu_{\text {Adhesive }}=\beta_{0}+\beta_{1}\left(V_{i}\right)+\beta_{2}\left(P_{i}\right)
$$




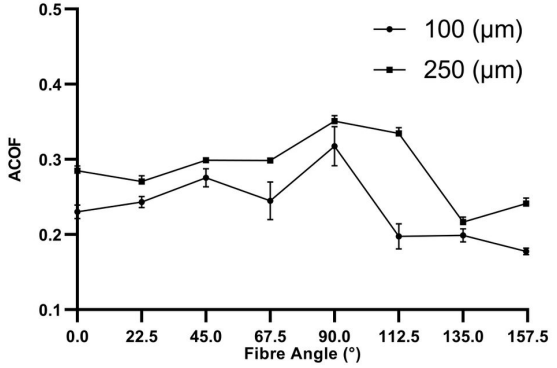

(a)

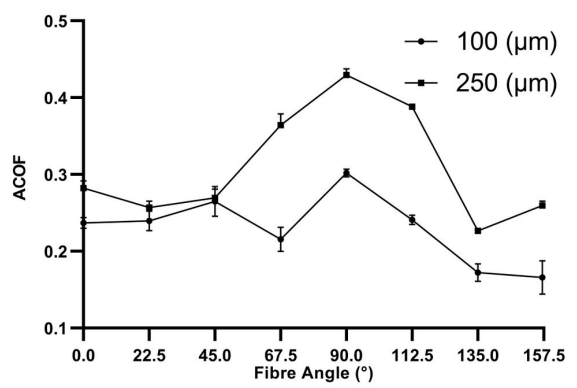

(c)

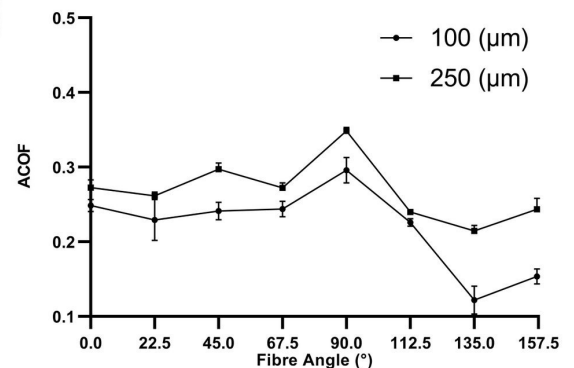

(b)

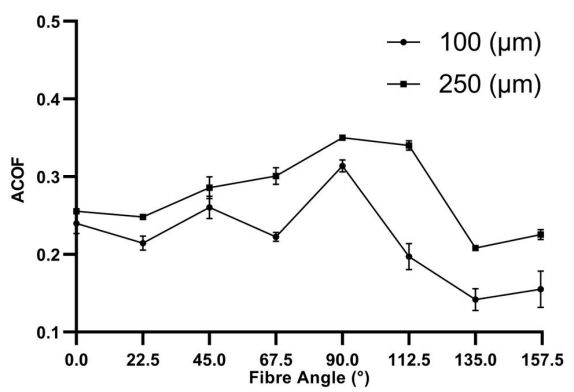

(d)

Figure 6. Effects of fibre angle on ACOF with machining velocities: (a) $1 \mathrm{~m} / \mathrm{min}$, (b) $5 \mathrm{~m} / \mathrm{min}$, (c) $10 \mathrm{~m} / \mathrm{min}$ and (d) $15 \mathrm{~m} / \mathrm{min}$.

Table 2. MLR Coefficients.

\begin{tabular}{lllll}
\hline $\boldsymbol{\Theta}$ & $\boldsymbol{\beta}_{\mathbf{0}}$ & $\boldsymbol{\beta}_{\mathbf{1}}$ & $\boldsymbol{v} \boldsymbol{\beta}_{\mathbf{2}}$ & $\mathbf{R 2}$ \\
\hline 0 & 0.2803690 & -0.0015720 & -0.0012253 & 0.93 \\
22.5 & 0.1644200 & 0.0050902 & -0.0006417 & 0.837 \\
45 & 0.0974485 & -0.0004083 & 0.0001334 & 0.905 \\
67.5 & 0.3047650 & -0.0053778 & -0.0006111 & 0.905 \\
90 & 0.1211090 & 0.0130631 & -0.0003668 & 0.738 \\
112.5 & 0.1763290 & -0.0039313 & 0.0008020 & 0.679 \\
135 & 0.1679290 & -0.0069309 & 0.0006020 & 0.837 \\
157.5 & 0.1060290 & 0.0018082 & 0.0007306 & 0.949 \\
\hline
\end{tabular}

\section{Numerical Work}

\subsection{Introduction}

This section will discuss the issues faced when implementing dynamic experimental frictional data-collected from the previous experimental section-into an explicit machining simulation though the use of ABAQUS CAE finite element solver. Dynamic friction coefficients are not possible in ABAQUS CAE GUI, and this section will discuss how this problem was overcome. The main advantage of initially using FE is to allow for a more accurate method of friction serration. As previously mentioned, ABAQUS/CAE by default only requires $\mathrm{ADCOF}$ as an input for the contact properties, meaning that the ACOF data from the experimental work needs to be separated-this was achieved by using an inverse modelling technique. Once the data had been separated, MLR was then carried out in the ADCOF data to build a dynamic friction model for WC-CFRPs.

Another key factor of ABAQUS CAE is that the built-in Coulomb friction model does not depend on any factors, apart from a constant value widely accepted at approximately 0.3 for CFRP/WC variables-this is a major assumption in previous numerical studies. CFRPs also have the added difficulty of having a fibre orientation-dependent coefficient of friction, 
further highlighting the need for a detailed friction model to remove key uncertainties in FE modelling of CFRP machining operations.

The final separated ADCOF data were then applied though a user-defined subroutine, in a number of numerical tribological studies, to discuss the benefits of using the newly proposed dynamic friction model.The Finite element model used for the friction separation method can be seen in Figure 7.

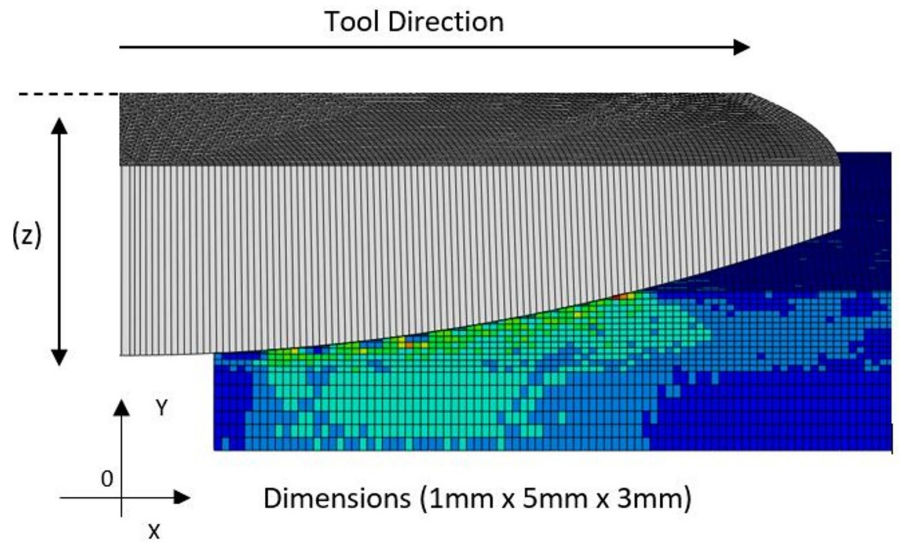

Figure 7. 2D Cross section of the 3D FE model.

\subsection{Material Model}

In the public domain, high-quality material behaviour models are essential to perform accurate simulations. The greatest complexity in material models is usually found in the design of reliable damage models. In the case of composite materials, the development of a damage model is complex due to the interaction of fibre and matrix damage types. This work would complicate this research focused on the study of tool/workpiece friction. Therefore, this work implements the model implemented by Cepero-Mejias et al. in various fields of composite machining modelling such as chip formation [29,30], tool wear [3] and sub-surface damage $[1,31,32]$ to obtain high-quality predictions.

This model consists of an orthotropic linear-elastic model before any initiation of damage occurs. Damage initiation is calculated using a Hashin-Puck hybrid model considering four types of damage: fibre traction ( $\mathrm{ft}$ ), fibre compression $(\mathrm{fc})$, matrix traction in ply $(\mathrm{mt} 2)$, matrix compression in ply (mc2), matrix traction in the thickness direction ( $\mathrm{mt} 3$ ) and matrix compression in the thickness direction (mc3). Exposure factors $\left(F_{I}\right)$ control damage initiation with the equations presented below.

- $\quad$ Fibre traction $\left(\sigma_{11} \geq 0\right)$

$$
F_{f t}=\left(\frac{\sigma_{11}}{X_{T}}\right)^{2}+\left(\frac{\sigma_{12}}{S_{12}}\right)^{2}+\left(\frac{\sigma_{13}}{S_{13}}\right)^{2} \geq 1
$$

- $\quad$ Fibre compression $\left(\sigma_{11}<0\right)$

$$
F_{f c}=\left|\frac{\sigma_{11}}{X_{C}}\right| \geq 1
$$

- $\quad$ Matrix Mode A in ply $\left(\sigma_{22} \geq 0\right)$

$$
F_{m t 2 a}=\sqrt{\left(\frac{\sigma_{12}}{R_{\perp \|}^{A}}\right)^{2}+\left(1-\frac{p_{\perp \|}^{(+)}}{R_{\perp \|}^{A}} R_{\perp}^{(+) A}\right)^{2}\left(\frac{\sigma_{22}}{R_{\perp}^{(+) A}}\right)^{2}}+\frac{p_{\perp \|}^{(+)}}{R_{\perp \|}^{A}} \sigma_{22} \geq 1
$$


- $\quad$ Matrix Mode B in ply $\left(\sigma_{22}<0\right.$ and $\left.\sigma_{22}>-R_{\perp \perp}^{A}\right)$

$$
F_{m c 2 b}=\sqrt{\left(\frac{\sigma_{12}}{R_{\perp \|}^{A}}\right)^{2}+\left(\frac{p}{R}\right)^{2} \sigma_{22}^{2}}+\left(\frac{p}{R}\right) \sigma_{22} \geq 1
$$

- $\quad$ Matrix Mode C in ply $\left(\sigma_{22} \leq-R_{\perp \perp}^{A}\right)$

$$
F_{m c 2 c}=\frac{1}{2\left[1+\left(\frac{p}{R}\right) R_{\perp \perp}^{A}\right]}\left[\left(\frac{\sigma_{12}}{R_{\perp \|}^{A}}\right)^{2}+\left(\frac{\sigma_{22}}{R_{\perp \perp}^{A}}\right)^{2}\right] \frac{R_{\perp \perp}^{A}}{-\sigma_{22}} \geq 1
$$

- $\quad$ Matrix traction in thickness direction $\left(\sigma_{33} \geq 0\right)$

$$
F_{m+3}=\left(\frac{\sigma_{33}}{Z_{T}}\right)^{2}+\left(\frac{\sigma_{13}}{S_{13}}\right)^{2}+\left(\frac{\sigma_{23}}{S_{23}}\right)^{2} \geq 1
$$

- Matrix compression in thickness direction $\left(\sigma_{33}<0\right)$

$$
F_{m c 3}=\left|\frac{\sigma_{33}}{Z_{C}}\right| \geq 1
$$

For brevity, the meaning of the terms stated in the above equations is not explained in this manuscript. The reader is referred to [5] for more information on the terms used in these equations. Once damage initiation occurs for a certain damage mode, a linear degradation based on energy criteria is applied to the stiffness matrix components associated with the matrix or fibre. This action is achieved by introducing matrix damage $\left(d_{m}\right)$, fibre damage $\left(d_{f}\right)$ and shear damage $\left(d_{s}\right)$ variables in the components that affect longitudinal, transverse or shear stiffness, as shown in Equation (13).

$$
\begin{aligned}
& C_{11}=E_{11}\left(1-d_{f}\right)\left[1-\left(1-d_{m 2}\right)\left(1-d_{m 3}\right) v_{23}^{2}\right] / A \\
& C_{12}=E_{22}\left(1-d_{f}\right)\left(1-d_{m 2}\right)\left[\left(1-d_{m 3}\right) v_{13} v_{23}+v_{12}\right] / A \\
& C_{22}=E_{22}\left(1-d_{m 2}\right)\left[1-\left(1-d_{f}\right)\left(1-d_{m 3}\right) v_{13} v_{13}\right] / A \\
& C_{13}=E_{33}\left(1-d_{f}\right)\left(1-d_{m 3}\right)\left[\left(1-d_{m 2}\right) v_{12} v_{23}+v_{13}\right] / A \\
& C_{33}=E_{33}\left(1-d_{m 3}\right)\left[1-\left(1-d_{f}\right)\left(1-d_{m 2}\right) v_{12} v_{21}\right] / A \\
& C_{23}=E_{33}\left(1-d_{m 2}\right)\left(1-d_{m 3}\right)\left[\left(1-d_{f}\right) v_{12} v_{31}+v_{23}\right] / A \\
& C_{44}=G_{12}\left(1-d_{f}\right)\left(1-d_{m 2}\right) \\
& C_{55}=G_{13}\left(1-d_{f}\right)\left(1-d_{m 3}\right) \\
& C_{66}=G_{23}\left(1-d_{m 2}\right)\left(1-d_{m 3}\right)
\end{aligned}
$$

Here, $d_{f}=\max \left\{d_{f t}, d_{f c}\right\} ; d_{m 2}=\max \left\{d_{m t 2}, d_{m c 2}\right\} ; d_{m 3}=\max \left\{d_{m t 3}, d_{m c 3}\right\} d_{I} \in[0,1]$ and $I=(f t, f c, m t 2, m c 2, m t 3, m c 3)$ with $\quad A=1-\left(1-d_{f}\right)\left(1-d_{m 2}\right) v 12 v_{21}-(1-$ $\left.d_{m 2}\right)\left(1-d_{m 3}\right) v_{23}^{2}-\left(1-d_{f}\right)\left(1-d_{m 3}\right) v_{13} v_{31}-2\left(1-d_{f}\right)\left(1-d_{m 2}\right)\left(1-d_{m 3}\right) v_{12} v_{31} v_{23}$.

These damage variables evolve from 0 (no damage) to 1 (total damage), guaranteeing a linear degradation of the mechanical properties of each element until the damage mode fracture energy is reached. Note that the maximum matrix damage is set to 0.95 to avoid distortional problems [19] and consider the remaining stiffness that a cracked matrix ply brings to adjacent plies [33]. This degradation of the mechanical properties is carried out between an initial equivalent displacement value $\left(\delta_{I, e q}^{0}\right)$ and a final equivalent displacement value $\left(\delta_{I, e q}^{f}\right)$, calculated with Equations (14) and (15). Finally, Table 3 shows the fracture energies of each damage mode used in this investigation.

$$
\delta_{I, e q}^{0}=\frac{\delta_{I, e q}}{F_{I}}
$$




$$
\begin{gathered}
\delta_{I, e q}^{f}=\frac{2 G_{I}^{C}}{\sigma_{I, e q}} \\
d_{I}=\frac{\delta_{I, e q}^{f}\left(\delta_{I, e q}-\delta_{I, e q}^{0}\right)}{\delta_{I, e q}\left(\delta_{I, e q}^{f}-\delta_{I, e q}^{0}\right)} \quad\left(d_{I} \in[0,1] \text { and } I=(f t, f c, m t 2, m c 2, m t 3 \text { and } m c 3)\right)
\end{gathered}
$$

Table 3. Critical fracture toughness.

\begin{tabular}{ccccccc}
\hline $\mathbf{N} / \mathbf{m m}$ & $G_{f t}^{c}$ & $G_{f c}^{c}$ & $G_{m t 2}^{c}$ & $G_{m c 2}^{c}$ & $G_{m t 3}^{c}$ & $G_{m c 3}^{c}$ \\
\hline$G_{I}^{C}$ & 100 & 100 & 1 & 1 & 1 & 1 \\
\hline
\end{tabular}

\subsection{Inverse Modelling Friction Separation}

The experimental apparatus was modelled in an ABAQUS FE explicit domain, a mesh sensitivity study was undertaken and a $5 \mu \mathrm{m}$ C3D8R element size was used. A hard penalty contact algorithm was selected along with a rigid boundary condition for the pin. A material percentage damage to failure of $95 \%$ was used, which is a regularly accepted figure in the literature [19].

A linear response was observed between $\mathrm{ACOF}$ and $\mathrm{ADCOF}$, which was expected due to the way in which the Coulomb friction model is implemented in ABAQUS. This greatly reduces the number of iterations needed in the inverse modelling of the friction separation Figure 8. Separation was achieved by inputting ADCOF into the open-loop tribo simulation through a standard Coulomb friction model. Values 0.05 and 0.2 were used; however, due to the linear response, any values within the range could have been used. Once the global forces stabilised, ACOF could be calculated. Knowing the ACOF and ADCOF from each simulation and the ACOF from the experimental results, the experimental ADCOF could be established.
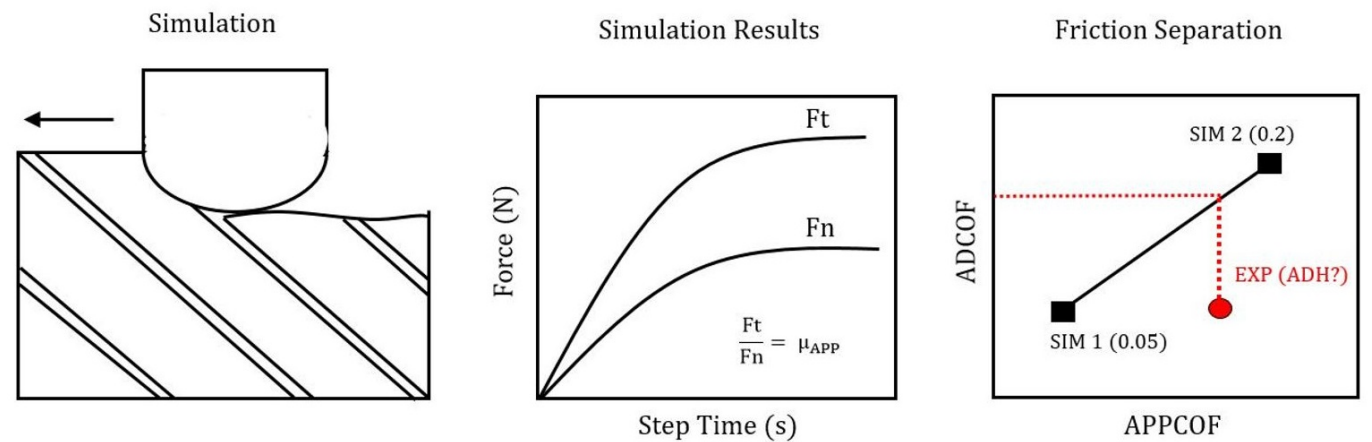

Figure 8. Friction separation flowchart.

The separation ratios were then applied to the ACOF MLR data to create ADCOF MLR data to be used in further FE simulations, shown in Table 4. Due to the complex physics which accrue throughout different fibre angles, buckling, debonding, and tearing, ADHCOF has been separated into independent fibre angle MRL data-this greatly improved its accuracy.

$$
\mu_{\text {Adhesive }}=\left(\beta_{0}+\beta_{1}\left(V_{i}\right)+\beta_{2}\left(P_{i}\right)\right.
$$


Table 4. MLR Data.

\begin{tabular}{lllll}
\hline $\boldsymbol{\Theta}$ & $\boldsymbol{\beta}_{\mathbf{0}}$ & $\boldsymbol{\beta}_{\mathbf{1}}$ & $\boldsymbol{\beta}_{\mathbf{2}}$ & $\mathbf{R 2}$ \\
\hline 0 & 0.052488 & 0.006025 & 0.0003908 & 0.847 \\
22.5 & 0.197959 & -0.001155 & -0.000634 & 0.793 \\
45 & 0.240492 & -0.005277 & -0.000341 & 0.786 \\
67.5 & 0.18297 & 0.007671 & -0.000392 & 0.466 \\
90 & 0.149911 & 0.013133 & -0.000753 & 0.715 \\
112.5 & 0.081576 & -0.001422 & 0.0008751 & 0.634 \\
135 & 0.156666 & 0.014112 & -0.000684 & 0.689 \\
157.5 & 0.075583 & 0.000894 & 0.000419 & 0.7111 \\
\hline
\end{tabular}

\subsection{Finite Element and Friction Modelling}

During a machining FE simulation, when the tool and workpiece come into contact, an algorithm is used to determine how the nodes and nodal surfaces interact with one another. During this stage, a mechanical constrained formation is applied, either a penalty or kinematic contact method, in which local contract pressures, sliding velocities and temperatures are calculated.

These contact variables can then be supplied to the frictional model, meaning that the contact algorithm is only physically representative if the fictional model is accurate.

\subsection{Empirical Friction Model}

A dynamic friction model for WC-CO and UD CFRPs, which is a function of fibre orientation, sliding velocity and applied force, is the proposed solution to uncertainty present when using a contact COULOMB model. This empirical solution has been implemented using a user-defined subroutine, which does not remove workload from the FE solver, as the material model and contact algorithm would still need to compute the normal forces. Even so, the dynamic frictional changes and their effect on first-order and secondary results are better accounted for.

\subsection{GUI Tangential Behaviour}

The simplest method which has previously been discussed is to apply a constant friction coefficient through the contact property in the GUI in ABAQUS. This method has the benefit of being robust and simple to apply, but does not capture dynamic frictional changes. This method also has the ability to use slip rate-, contact pressure- and temperature-dependent data, which is a great asset for the GUI program. However, these data are applied in a spreadsheet format and do not allow for a single empirical model to be applied.

\subsection{VFRIC and VFRICTION Subroutine}

VFRIC user subroutine can be used to define frictional behaviour between a contact pair of surfaces, when the typical Coulomb model is too restrictive and a more complex shear transition between the surfaces is present. VFRIC can be used to control other solutiondependent state variables, and would allow for a single constitutive friction model to be applied, unlike the GUI format. However, the main disadvantage of this subroutine is that it can only be used with the 'surface to surface' contact algorithm and not with 'general contact' (GC). Surface to surface also has the issue of self intersecting internal nodes during the simulation, which can affect the simulation's ability to complete without computational errors.

VFRICTION is very similar to VFRIC, and is programmed in the same manner but has fewer variables that it can control and can be used with the GC algorithm. The GC algorithm is thought to yield better results for machining simulations than the surface-tosurface contact algorithm, although it can only do so in a 3D case, which greatly increases the computational time. However, pressure is a $3 \mathrm{D}$ phenomenon and for this reason, VFRICTION was the chosen subroutine for this study. A 3D benchmark was carried out 
against ABAQUS/CAE built-in Coulomb friction and VFRICTION, in which complete correlation was achieved, giving good confidence in the VFRICTON subroutine.

\section{Numerical Pressure Measurements and Conversion}

The final goal of this numerical section is to achieve a pressure-, speed- and fibre angledriven friction model, which works on a nodal scale developed with experimental factors on a global scale-meaning a method of measuring pressure on an experimental level which correlates with pressures measured on a nodal scale is imperative. Experimental pressure was calculated as previously discussed (Equation (18)) using the global load on the pin and the feed depth. To ensure that the nodal pressures and this global pressure were valid, a benchmark was undertaken. Nodal pressure was outputted from the VFRICTION subroutine Equation (19), with fNormal(K) being the nodal force and AreaCont(K) equalling the instantaneous area in contact. CPress is an inbuilt command in ABAQUS/CAE, which is calculated using the net normal force loads, CNORNF and the element area in contact with the pin's surface.

$$
\begin{gathered}
\operatorname{ContactArea}(A)=2 \pi r z \\
\text { GlobalPressure }=f_{n} / A \\
\operatorname{NodalPressure}(K)=\frac{f \operatorname{Normal}(K)}{\operatorname{AreaCont}(K)}
\end{gathered}
$$

Figure 9 shows a scattering of pressures for both nodal pressure measurements. This is to be expected as these instantaneous values of pressures are constantly changing throughout the simulation. This is due to the material model's response and its resulting force (fn) on the pin. What is more interesting is the scale of forces, with both global and nodal methods peaking at $200 \mathrm{MPa}$, which gives confidence overall in using this method and in Equation (18).

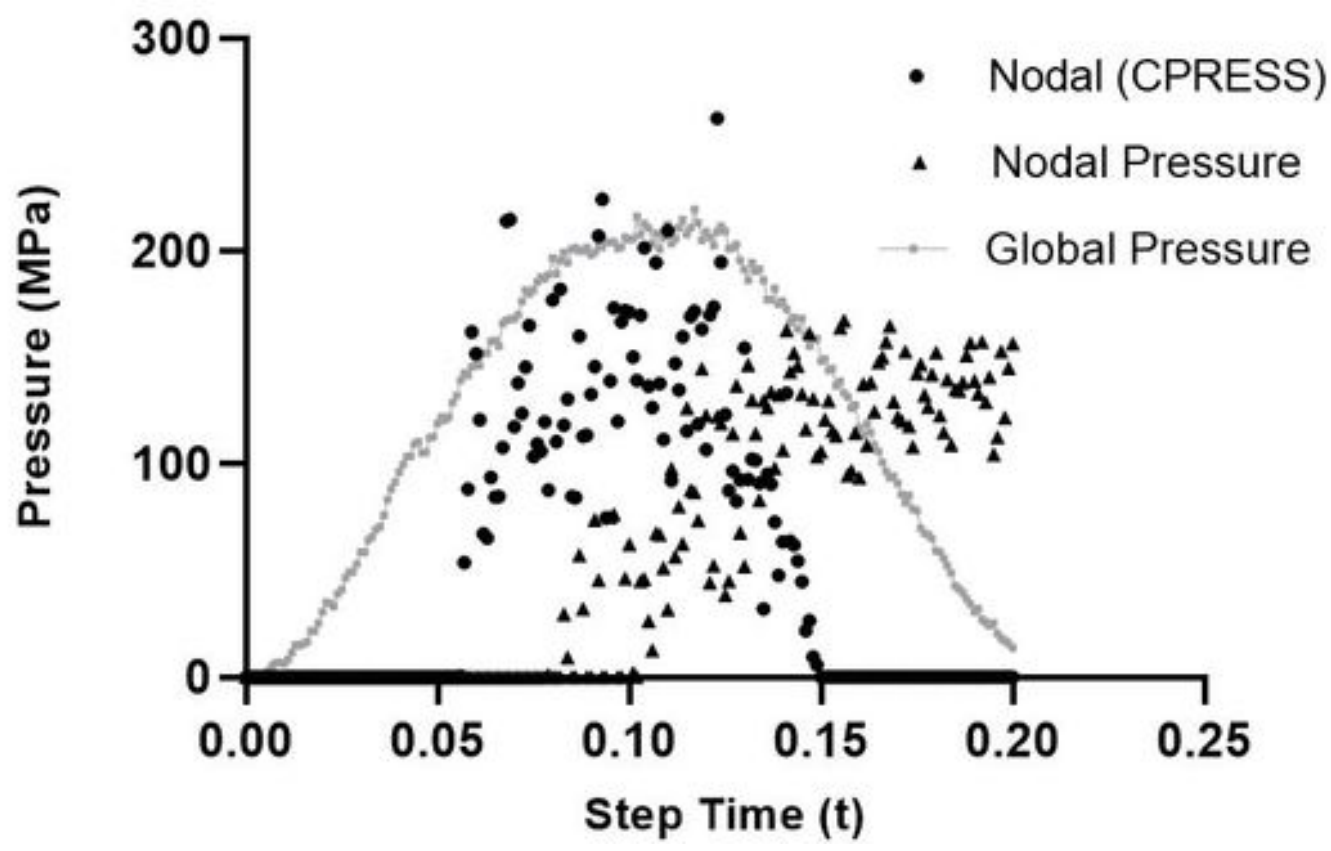

Figure 9. CPress, NPress and GPress comparison.

\section{Dynamic Friction Implementation}

Using the adhesive friction model developed using the friction separation method previously discussed, a number of validation simulations were tested. This was to demonstrate the robustness and accuracy of the newly proposed dynamic friction model. Figure 10 shows the order in which the VFRICTION subroutine (Listing 1) is computed, which is 
called at every numerical interval and iterated throughout the FE simulation. Incorporating the required subroutines (VUMAT, VFRICTION, and VUFIELD) with multi-thread computation, this was achieved using common blocks. Using mpi threads did not require a locking and unlocking function in order for the computation to work correctly [34].

Listing 1. Subroutine code.

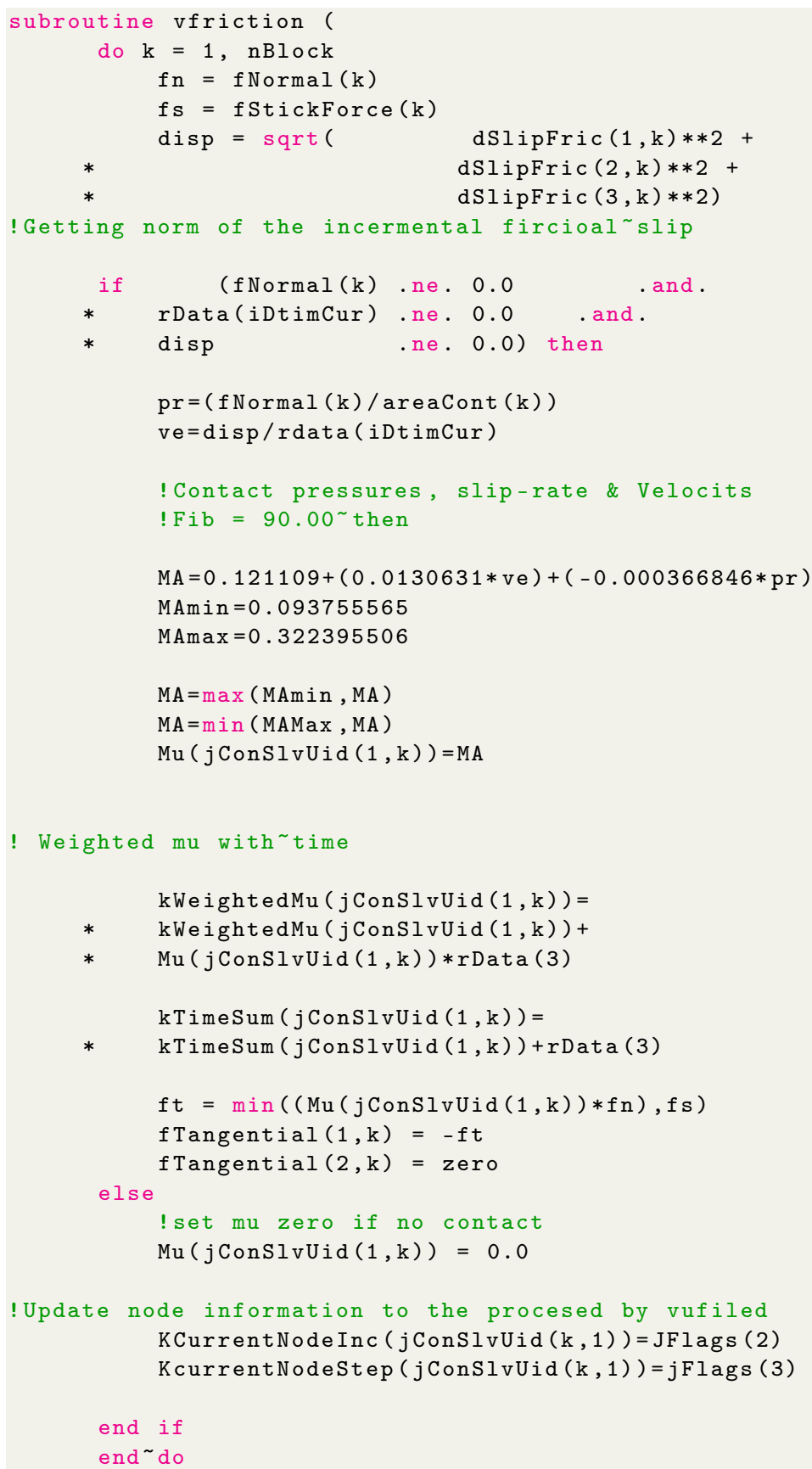




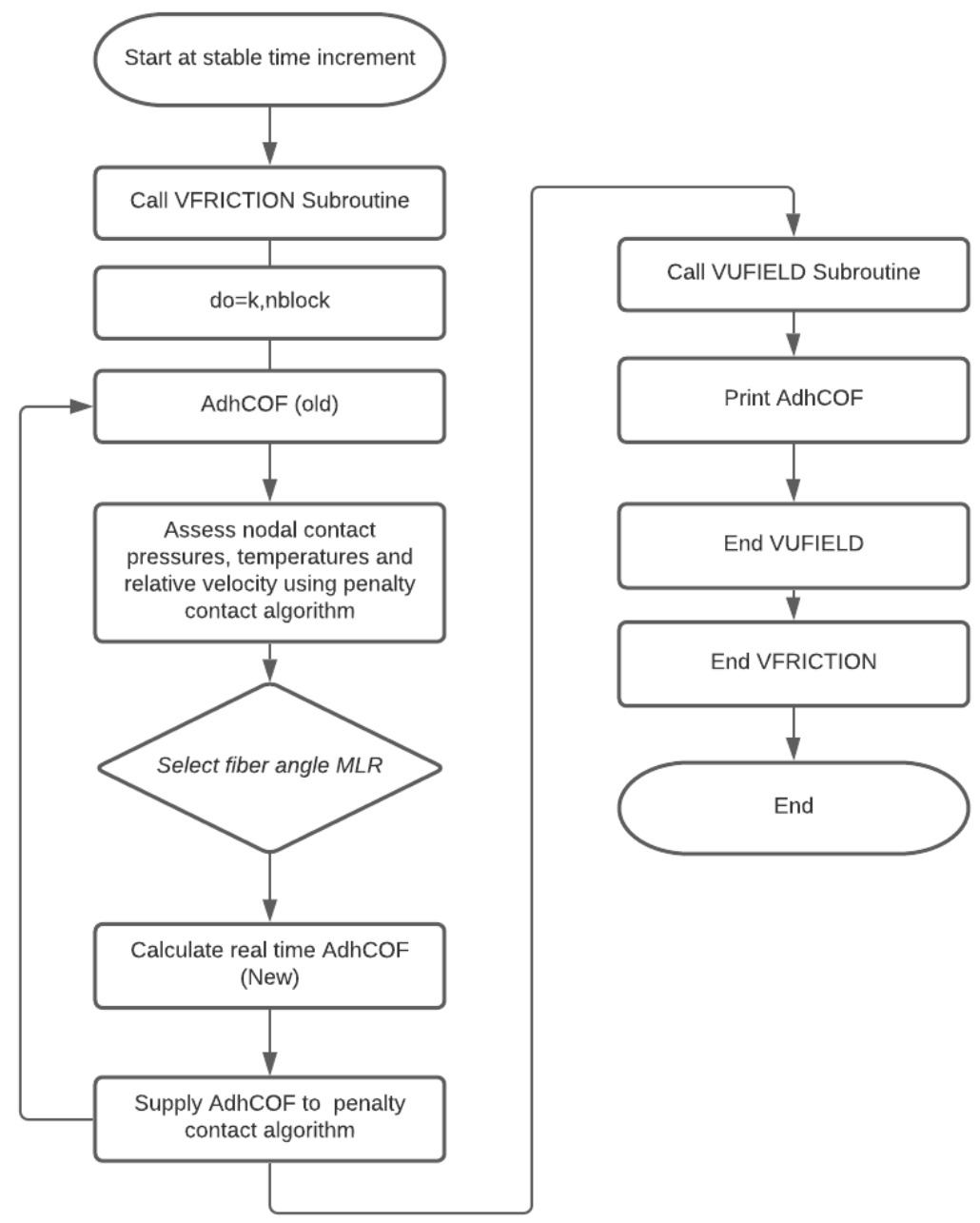

Figure 10. Subroutine implementation.

\section{Results and Discussion}

All open-loop tribo interactions were simulated using the same methodology previously discussed, although the dynamic friction model was implemented through the VFRICTION subroutine for these simulations. Comparing VFRICTION, constant and experimental forces and ACOF show good correlation (Table 5, Figures 11 and 12). Positive fibre angels (0-90) show the least initial error with 0.2 AHCOF performing relatively well. However, VFRICTION still gave improvements of $1 \%, 13 \%$ and $12 \%$ for $\mathrm{Fn}, \mathrm{Ft}$ and ACOF, respectively. Negative fibre angles showed the highest improvements, of $18 \%, 18 \%$ and $26 \%$ for Fn, $\mathrm{Ft}$ and ACOF respectively. Negative angles are predominantly harder to model due to the increased complexity in failure modes and chip formation, which causes numerical instability. Therefore, the results collected using VFRICTION at these angles are promising for the methodology. However, some caution should be taken with this set as the R2 values for $\theta$ (90 and 112.5) were relatively low due to experimental difficulties when machining these negative angles. 
Table 5. Percentage difference for constant ACOF vs. proposed dynamic friction model.

\begin{tabular}{ccccccc}
\hline $\boldsymbol{\theta}$ & FN VFRI & FN CON & FT VFRI & FT CON & ACOF VFRIC & ACOF CON \\
\hline 0 & $-5 \%$ & $0 \%$ & $-2 \%$ & $-8 \%$ & $-5 \%$ & $-8 \%$ \\
22.5 & $1 \%$ & $-3 \%$ & $-3 \%$ & $-10 \%$ & $-2 \%$ & $-9 \%$ \\
45 & $4 \%$ & $-19 \%$ & $-4 \%$ & $-18 \%$ & $-9 \%$ & $-54 \%$ \\
67.5 & $4 \%$ & $-19 \%$ & $-4 \%$ & $-18 \%$ & $-9 \%$ & $-54 \%$ \\
90 & $7 \%$ & $48 \%$ & $-2 \%$ & $138 \%$ & $11 \%$ & $166 \%$ \\
112.5 & $8 \%$ & $-22 \%$ & $-12 \%$ & $-32 \%$ & $-19 \%$ & $-53 \%$ \\
135 & $12 \%$ & $-39 \%$ & $-35 \%$ & $-61 \%$ & $-6 \%$ & $-39 \%$ \\
157.5 & $10 \%$ & $-23 \%$ & $-28 \%$ & $-35 \%$ & $-36 \%$ & $-37 \%$ \\
Ranges & & & & & $-2 \%$ & $-11 \%$ \\
\hline $0-90$ & $2 \%$ & $1 \%$ & $-3 \%$ & $16 \%$ & $-43 \%$ & \\
$112.5-157$ & $10 \%$ & $-28 \%$ & $-25 \%$ & & $-3 \%$ \\
\hline
\end{tabular}

$\begin{array}{lllll}\text { Experimental (Ft) } & & \text { Experimental (Fn) } & & \text { Experimental (ACOF) } \\ \text { VFICTION (Ft) } & \text { VFICTION (Fn) } & & \text { VFICTION (ACOF) } \\ \text { CONSTANT (Ft) } & \text { CONSTANT (Fn) } & & \text { CONSTANT (ACOF) }\end{array}$

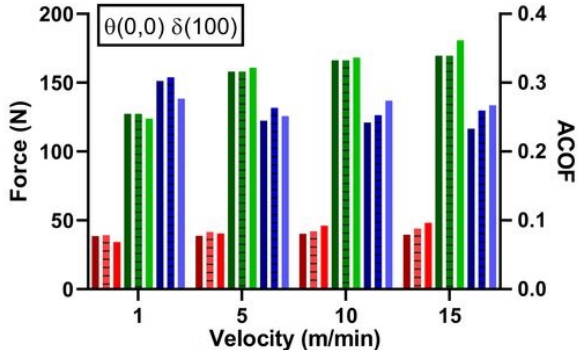

(a)

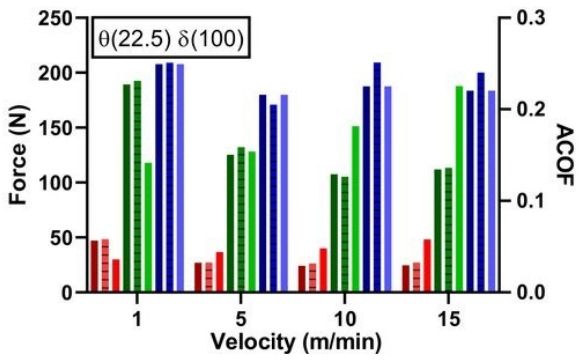

(c)

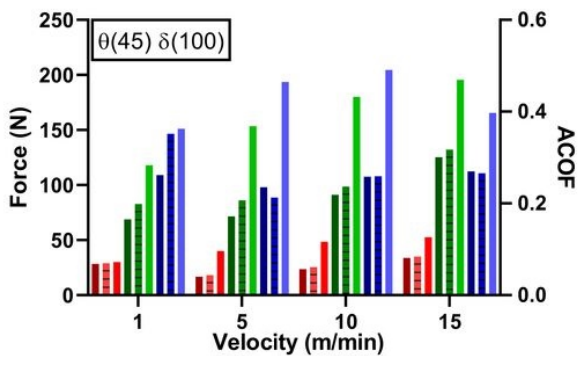

(e)

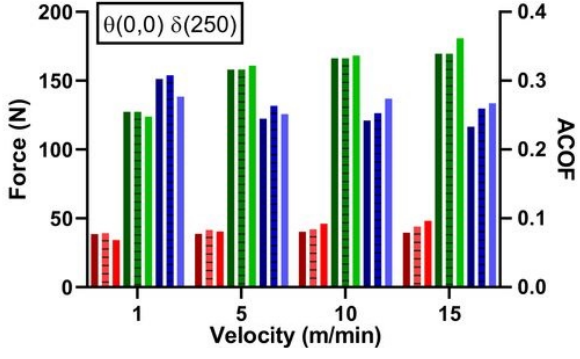

(b)

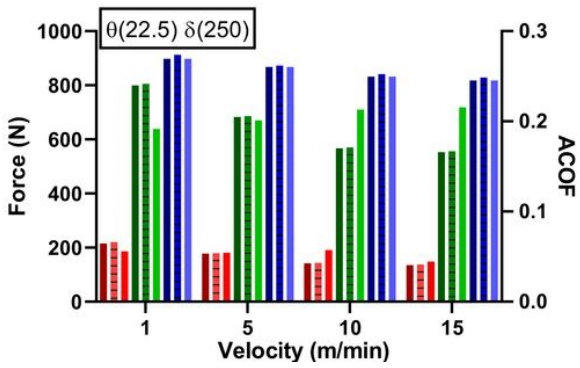

(d)

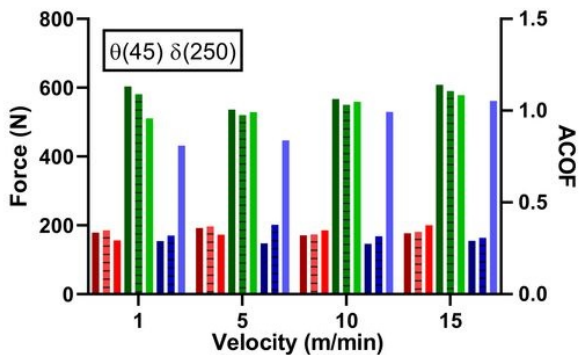

(f)

Figure 11. Experimental Results: FE Comparison of Dynamic Friction Model vs. Constant Friction Coefficient for Open-Loop Tribology. 


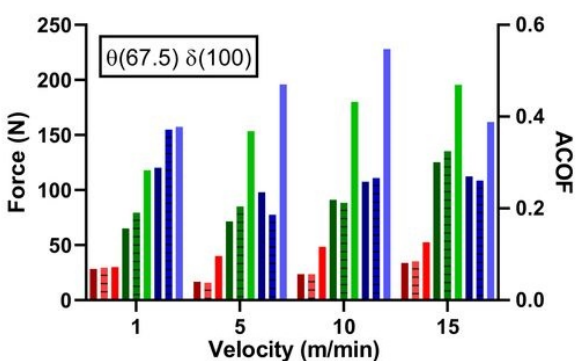

(a)

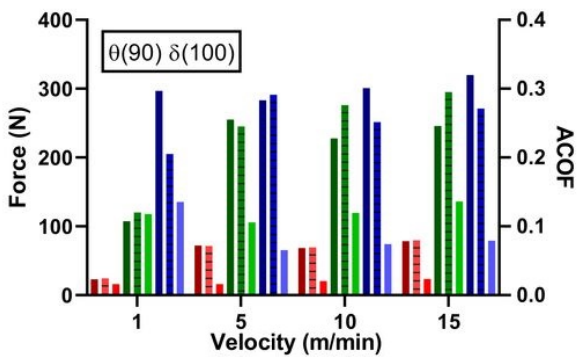

(c)

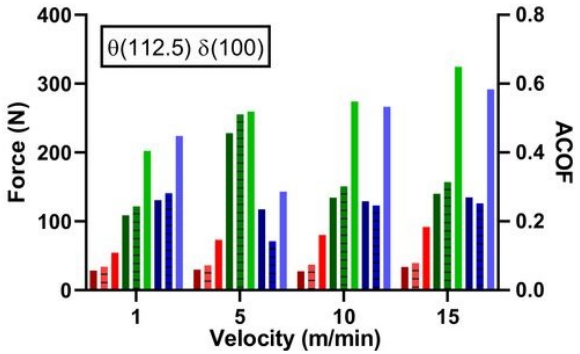

(e)

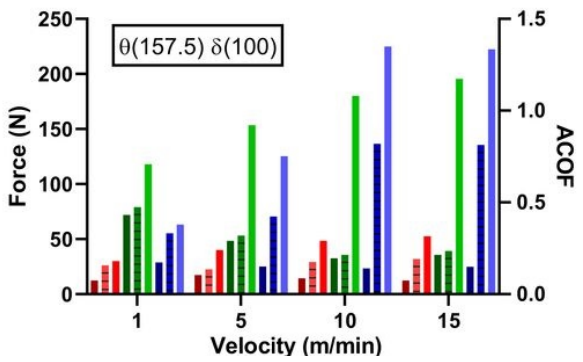

(g)

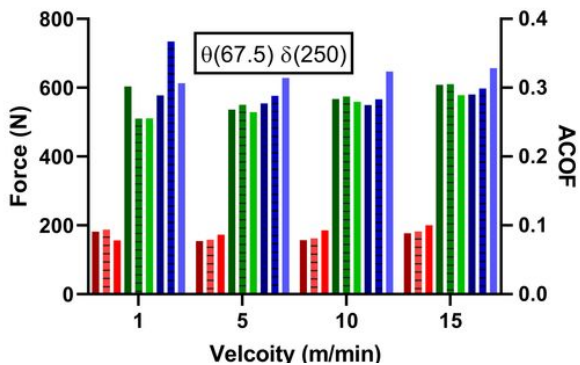

(b)

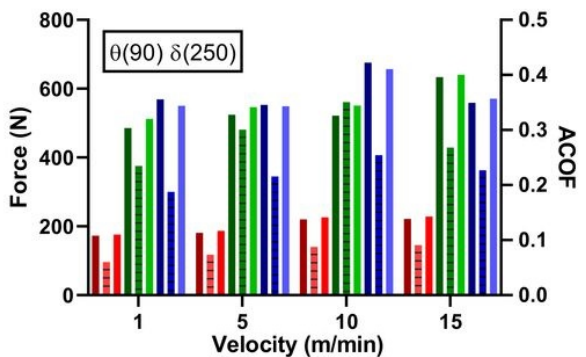

(d)

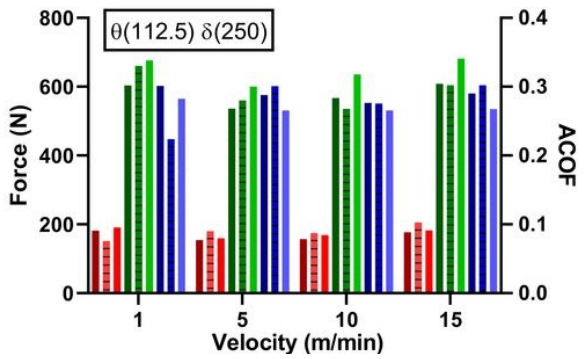

(f)

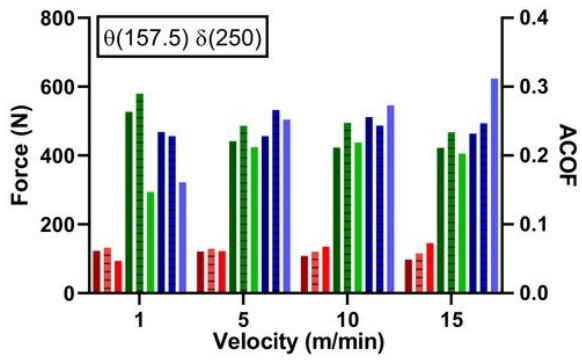

(h)

Figure 12. Experimental Results: FE Comparison of Dynamic Friction Model vs. Constant Friction Coefficient for Open-Loop Tribology.

Benefits of using the VFRICTION subroutine over a constant ACOF can be seen below, with VFRICTION allowing dynamic friction across the surface in contact, unlike its constant counterpart, which is thought to be more physiologically accurate to the real-word situation. The constant friction model only allows for a step function (0-0.2) ADCOF when the elements of the pin and CFRP come into contact. In comparison, VFRICTION allows a dynamic function of ADCOF driven with data collected from the experiment, which can be seen graphically bellow in Figure 13b. 


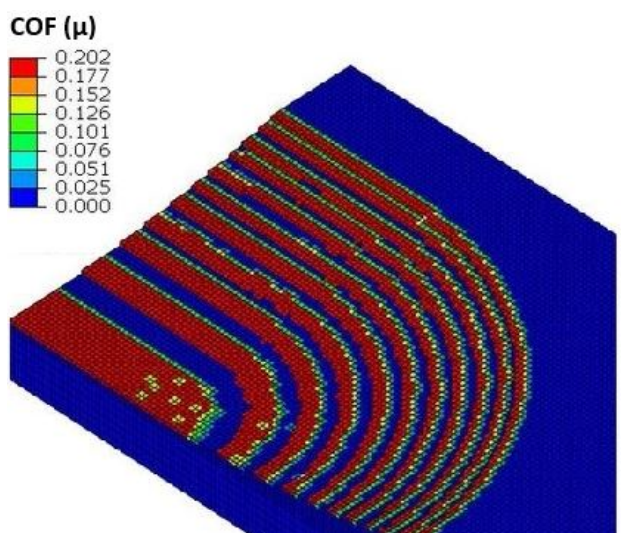

(a)

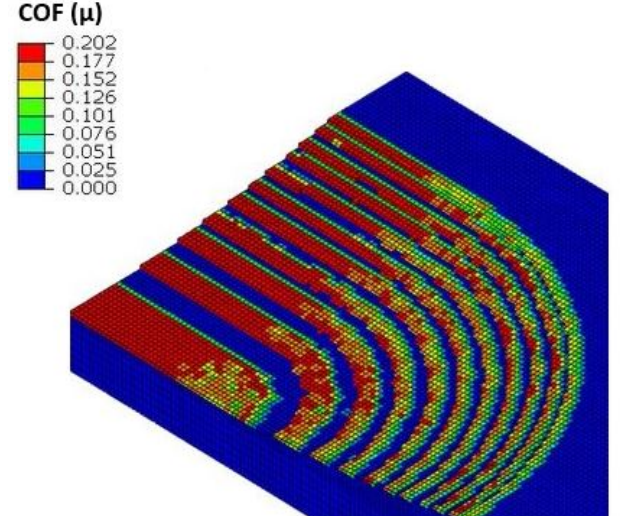

(b)

Figure 13. A section of the tribo open-loop FE model with the pin removed-constant (a); VFRICTION (b).

Using this methodology removes the uncertainty and ability to adjust COF values to match up real-world machining forces. However, it does further complicate CFRP machining simulations and requires researchers to carry out not only material testing but also open-loop tribological testing before developing FE simulations.

\section{Conclusions}

This study has shown the current uncertainty in literature found when constant friction coefficients are implemented for FE machining simulations, whilst highlighting the benefits of using a dynamic friction model, to capture in more detail the factors that affect the tool-workpiece interaction. To the authors' knowledge, no other study is yet to link open-loop tribological data for CFRPs, with a well-validated FE material model. Further improvements could be made with the available dataset, and a higher number of feeds, speeds, and fibre angles could be tested. Further, differing CFRP compositions and temperature effects would improve the validity of the proposed friction model, although the experimental open-loop tribology setup, FE modelling methodology, and dynamic friction model implementation have set the framework for further study in the sector.

- $\quad$ This novel CFRP/WC dynamic frictional model and novel implementation yielded a more accurate force response for each fibre angle studied.

- The dynamic friction model was shown to over predict $2 \%$ at $100 \mu \mathrm{m}$ and under predict $4 \%$ at $250 \mu \mathrm{m}$, which should improve with more data to the tune friction model, compared with an average $10 \%$ when using a constant value.

- Velocity changes have a much greater effect on the contact friction model than pressure.

- A limitation of this study is that it does not account for temperature effects in both the experimental trial and numerical domain.

- $\quad 90^{\circ}$ showed the least comparison for both dynamic and constant approaches.

Author Contributions: O.S.; investigation, formal analysis, writing-original draft preparation, F.C.-M.; User-Defined Material Model, coding, Finite-Element supervision, J.P.A.F.; supervision; K.K.; supervision. All authors have read and agreed to the published version of the manuscript.

Funding: This work was funded by the Engineering and Physical Sciences Research Council (EPSRC) institution with the grant EP/L016257/2.

Institutional Review Board Statement: Not applicable.

Informed Consent Statement: Not applicable.

Data Availability Statement: The data presented in this study are available on request from the corresponding author. 
Acknowledgments: A special mention is deserved to the Industrial Doctoral Centre (IDC) of Sheffield for their effective technical support in the development of this project.

Conflicts of Interest: The authors declare no conflict of interest.

\section{References}

1. Cepero-Mejías, F.; Curiel-Sosa, J.; Zhang, C.; Phadnis, V. Effect of cutter geometry on machining induced damage in orthogonal cutting of UD polymer composites: FE study. Compos. Struct. 2019, 214, 439-450. [CrossRef]

2. Shetty, N.; Shahabaz, S.M.; Sharma, S.S.; Divakara Shetty, S. A review on finite element method for machining of composite materials. Compos. Struct. 2017, 176, 790-802. [CrossRef]

3. Cepero-Mejias, F.; Duboust, N.; Phadnis, V.A.; Kerrigan, K.; Curiel-Sosa, J.L. A novel finite element method approach in the modelling of edge trimming of CFRP laminates. Appl. Sci. 2021, 11, 4743. [CrossRef]

4. Hashin, Z.; Liu, K.; Lewis, F.; Lebret, G.; Taylor, D.; Kawai, M.; Morishita, M.; Tomura, S.; Takumida, K.; Zhang, J.Z.J.; et al. Failure Criteria for Unidirectional FibreComposites. Compos. Sci. Technol. 2015, 69, 683-706. [CrossRef]

5. Puck, A.; Deuschle, H.M. Progress in the Puck Failure Theory for Fibre Reinforced Composites: Analytical solutions for 3D-stress. Compos. Sci. Technol. 2002, 62, 371-378. [CrossRef]

6. Lapczyk, I.; Hurtado, J.A. Progressive damage modeling in fiber-reinforced materials. Compos. Part A Appl. Sci. Manuf. 2007, 38, 2333-2341. [CrossRef]

7. Priest, J.; Ghadbeigi, H.; Ayvar-Soberanis, S.; Liljerehn, A. Effects of coefficient of friction coupled with a deformation dependent friction model in cutting simulations. Procedia CIRP 2021, 102, 429-434. [CrossRef]

8. Filice, L.; Micari, F.; Rizzuti, S.; Umbrello, D. A critical analysis on the friction modelling in orthogonal machining. Int. J. Mach. Tools Manuf. 2007, 47, 709-714. [CrossRef]

9. Haglund, A.J.; Kishawy, H.A.; Rogers, R.J. An exploration of friction models for the chip-tool interface using an Arbitrary Lagrangian-Eulerian finite element model. Wear 2008, 265, 452-460. [CrossRef]

10. Cepero-Mejías, F.; Curiel-Sosa, J.L.; Blázquez, A.; Yu, T.T.; Kerrigan, K.; Phadnis, V.A. Review of recent developments and induced damage assessment in the modelling of the machining of long fibre reinforced polymer composites. Compos. Struct. $2020,240$. [CrossRef]

11. Santiuste, C.; Soldani, X.; Miguélez, M.H. Machining FEM model of long fiber composites for aeronautical components. Compos. Struct. 2010, 92, 691-698. [CrossRef]

12. Lafaye, S.; Gauthier, C.; Schirrer, R. The ploughing friction: Analytical model with elastic recovery for a conical tip with a blunted spherical extremity. Tribol. Lett. 2006, 21, 95-99. [CrossRef]

13. Nayak, D.; Bhatnagar, N.; Mahajan, P. Machining studies of ud-frp composites part 2: Finite element analysis. Mach. Sci. Technol. 2005, 9, 503-528. [CrossRef]

14. Nak-Ho, S.; Suh, N.P. Effect of fiber orientation on friction and wear of fiber reinforced polymeric composites. Wear 1979, 53, 129-141. [CrossRef]

15. Mkaddem, A.; El Mansori, M. Finite element analysis when machining UGF-reinforced PMCs plates: Chip formation, crack propagation and induced-damage. Mater. Des. 2009, 30, 3295-3302. [CrossRef]

16. Bhatnagar, N.; Nayak, D.; Singh, I.; Chouhan, H.; Mahajan, P. Determination of machining-induced damage characteristics of fiber reinforced plastic composite laminates. Mater. Manuf. Process. 2004, 19, 1009-1023. [CrossRef]

17. Wang, D.H.; Ramulu, M.; Arola, D. Orthogonal cutting mechanisms of graphite/epoxy composite. Part I: Unidirectional laminate. Int. J. Mach. Tools Manuf. 1995, 35, 1623-1638. [CrossRef]

18. Arola, D.; Sultan, M.B.; Ramulu, M. Finite Element Modeling of Edge Trimming Fiber Reinforced Plastics. J. Manuf. Sci. Eng. 2002, 124, 32. [CrossRef]

19. Lasri, L.; Nouari, M.; El Mansori, M. Modelling of chip separation in machining unidirectional FRP composites by stiffness degradation concept. Compos. Sci. Technol. 2009, 69, 684-692. [CrossRef]

20. Santiuste, C.; Díaz-Álvarez, J.; Soldani, X.; Miguélez, H. Modelling thermal effects in machining of carbon fiber reinforced polymer composites. J. Reinf. Plast. Compos. 2014, 33, 758-766. [CrossRef]

21. Zenia, S.; Ben Ayed, L.; Nouari, M.; Delamézière, A. Numerical analysis of the interaction between the cutting forces, induced cutting damage, and machining parameters of CFRP composites. Int. J. Adv. Manuf. Technol. 2015, 78, 465-480. [CrossRef]

22. Benhassine, M.; Rivière-Lorphèvre, E.; Arrazola, P.J.; Gobin, P.; Dumas, D.; Madhavan, V.; Aizpuru, O.; Ducobu, F. 2D simulations of orthogonal cutting of CFRP: Effect of tool angles on parameters of cut and chip morphology. AIP Conf. Proc. 2018, 1960. [CrossRef]

23. Challen, J.M.; Oxley, P.L. An explanation of the different regimes of friction and wear using asperity deformation models. Wear 1979, 53, 229-243. [CrossRef]

24. Mondelin, A.; Furet, B.; Rech, J. Characterisation of friction properties between a laminated carbon fibres reinforced polymer and a monocrystalline diamond under dry or lubricated conditions. Tribol. Int. 2010, 43, 1665-1673. [CrossRef]

25. Wang, X.M.; Zhang, L.C. An experimental investigation into the orthogonal cutting of unidirectional fibre reinforced plastics. Int. J. Mach. Tools Manuf. 2003, 43, 1015-1022. [CrossRef] 
26. Klinkova, O.; Rech, J.; Bergheau, J.M.; Drapier, S. Characterization of friction properties at the workmaterial/cutting tool interface during the machining of randomly structured carbon fibers reinforced polymer with carbide tools under dry conditions. Tribol. Int. 2011, 44, 2050-2058. [CrossRef]

27. Chardon, G.; Klinkova, O.; Rech, J.; Drapier, S.; Bergheau, J.M. Characterization of friction properties at the work material/cutting tool interface during the machining of randomly structured carbon fibers reinforced polymer with Poly Crystalline Diamond tool under dry conditions. Tribol. Int. 2015, 81, 300-308. [CrossRef]

28. Zemzemi, F.; Pasteur, L.; Koch, R. New tribometer designed for the characterisation of the friction properties at the tool/chip/workpiece interfaces in machining. Tribotest 2008, 74, 535-546. [CrossRef]

29. Cepero-Mejías, F.; Phadnis, V.A.; Kerrigan, K.; Curiel-Sosa, J.L. A finite element assessment of chip formation mechanisms in the machining of CFRP laminates with different fibre orientations. Compos. Struct. 2021, 268, 113966. [CrossRef]

30. Cepero-Mejias, F.; Curiel-Sosa, J.; Kerrigan, K.; Phadnis, V. Chip formation in machining of unidirectional carbon fibre reinforced polymer laminates: FEM based assessment. Procedia CIRP 2019, 85, 302-307. [CrossRef]

31. Cepero-Mejías, F.; Curiel-Sosa, J.; Kerrigan, K.; Phadnis, V. Study of the machining induced damage in UD-CFRP laminates with 28th CIRP fibre Study of the machining induced damage in UD-CFRP laminates with various orientations: FE fibre orientations: FE assessment A new me. Procedia CIRP 2020, 87, 366-371. [CrossRef]

32. Cepero-Mejias, F.; Phadnis, V.A.; Curiel-sosa, J.L. Machining induced damage in orthogonal cutting of UD composites: FEA based assessment of Hashin and Puck criteria. CIRP Conf. Model. Mach. Oper. 2019, 82, 332-337. [CrossRef]

33. Paris Carballo, F.; Cañas, J.; Marín, J. Introduction to Analysis and Design with Composite Materials; University of Seville, Higher Technical School of Engineers: Sevilla, Spain, 2008; p. 241.

34. Klocke, F.; Trauth, D.; Shirobokov, A.; Mattfeld, P. FE-analysis and in situ visualization of pressure-, slip-rate-, and temperaturedependent coefficients of friction for advanced sheet metal forming: Development of a novel coupled user subroutine for shell and continuum discretization. Int. J. Adv. Manuf. Technol. 2015, 81, 397-410. [CrossRef] 